\title{
Declining global per capita agricultural production and warming oceans threaten food security
}

\author{
Chris C. Funk • Molly E. Brown
}

Received: 19 November 2008 / Accepted: 17 June 2009/Published online: 25 July 2009

C The Author(s) 2009. This article is published with open access at Springerlink.com

\begin{abstract}
Despite accelerating globalization, most people still eat food that is grown locally. Developing countries with weak purchasing power tend to import as little food as possible from global markets, suffering consumption deficits during times of high prices or production declines. Local agricultural production, therefore, is critical to both food security and economic development among the rural poor. The level of local agricultural production, in turn, will be determined by the amount and quality of arable land, the amount and quality of agricultural inputs (fertilizer, seeds, pesticides, etc.), as well as farm-related technology, practices and policies. This paper discusses several emerging threats to global and regional food security, including declining yield gains that are failing to keep up with population increases, and warming in the tropical Indian Ocean and its impact on rainfall. If yields continue to grow more slowly than per capita harvested area, parts of Africa, Asia and Central and Southern America will experience substantial declines in per capita cereal production. Global per capita cereal production will potentially decline by $14 \%$ between 2008 and 2030. Climate change is likely to further affect food production, particularly in regions that have very low yields due to lack of technology. Drought, caused by anthropogenic warming in the Indian and Pacific
\end{abstract}

C. C. Funk $(\bowtie)$

U.S. Geological Survey Earth Resources Observation and Science

(EROS) Center, Department of Geography,

University of California Santa Barbara,

Ellison Hall, UCSB,

Santa Barbara, CA 96105, USA

e-mail: cfunk@usgs.gov

M. E. Brown

NASA Goddard Space Flight Center, Biospheric Sciences Branch,

Code 614.4,

Greenbelt, MD 20771-0001, USA
Oceans, may also reduce 21 st century food availability in some countries by disrupting moisture transports and bringing down dry air over crop growing areas. The impacts of these circulation changes over Asia remain uncertain. For Africa, however, Indian Ocean warming appears to have already reduced rainfall during the main growing season along the eastern edge of tropical Africa, from southern Somalia to northern parts of the Republic of South Africa. Through a combination of quantitative modeling of food balances and an examination of climate change, this study presents an analysis of emerging threats to global food security.

Keywords Global food security · Food availability . Agricultural production - Agricultural development . Climate change $\cdot$ Drought $\cdot$ Population growth

\section{Introduction}

Despite accelerating globalization, food security in most of the developing world depends upon local food production. Most rural citizens in developing nations are involved in agriculture (Lamb 2000). Also, most locally produced goods are consumed locally, so increasing local productivity and slowing population growth remains a central food security issue (Devereux and Maxwell 2001; Schmidhuber and Tubiello 2007). Over the past few years, energy price increases, biofuels and food scarcity have led to higher global food prices and price volatility. ${ }^{1}$ Rapidly increasing

\footnotetext{
${ }^{1}$ Between 2000 and 2007, increased biofuel demand contributed $30 \%$ of the weighted average increase of global grain prices. Personal communication, Joachim von Braun, IFPRI, October 2008.
} 
consumer prices limit food access. Increased price volatility reduces the benefit that small scale farmers derive from higher producer prices. Biofuels create competition between poor people in the developing world and energy consumers in the developed world. While higher priced commodities can bring direct benefits to farmers, these benefits will not be attained without significant and sustained investments in agriculture to increase production and in programs that reduce price volatility.

High and volatile food prices make local production even more important for food insecure regions. With high prices and continually increasing transportation costs, producing more locally will become an important source of vitality for programs focused on reducing poverty (FAO 2007). Connecting new innovations in crop research with improved outcomes in the developing world will likely require public sector investments (Delmer 2005). The recent entry into small-scale agricultural investment by the Bill and Melinda Gates Foundation has added new vibrancy to efforts focused on understanding barriers to increasing yields and sustaining production in the face of climate change.

This paper explores the convergence of three different trends: changes in agricultural production, changing climate and increasing population. Our assumption in the analyses presented is that that some countries will continue to have substantially less purchasing power than others over the next few decades. Although global trade is important, we assume that regions with small agriculturally based economies today are unlikely to transform themselves into industrial nations without first improving their agricultural productivity (Kates 2000; Fafchamps 2004; Haggblade 2007). The collision between increasing global food demand, competition for food with developed world energy consumers and increasingly difficult production conditions means that the food security situation is likely to worsen. Climate change will potentially bring reduced rainfall over some regions, and increased rainfall over others. The impact of these changes on agriculture must be anticipated and planned for (Verhagen et al. 2004).

To this end, this paper examines potential trends in per capita cereal production and rainfall. While other foods make substantial contributions to diets in many areas, per capita cereal production is indicative of general food availability in most developing countries. If the current rates of yield and population increases persist, many regions will see substantial declines in cereal availability. Greenhouse gas-induced reductions in monsoonal rainfall could exacerbate these grain shortages. On the other hand, relatively modest yield improvements in the least developed nations could lead to improved levels of per capita cereal production by 2030. If done sustainably, raising yields in these poorest nations may be the most technologically feasible way of addressing global cereal demands while reducing poverty and food insecurity.

\section{Data}

This study uses five sets of data (Table 1): agricultural statistics, population, observed rainfall and simulated rainfall from 10 different global climate models (Table 2). Based on simple equations describing the conservation of mass, momentum, radiation and other key dynamic factors, the global climate models simulate the full atmosphere at sub-daily time steps. These models may be constrained by observed sea surface temperatures (SSTs), or run combined with ocean models in full simulation mode. When constrained by observed SSTs, the models produce circulations resembling the observed atmosphere. This analysis uses 24 of these 20th century (1980-2000) simulations from 10 models to examine how well the models recreate observed seasonal rainfall variations between 1980 and 2000 (represented by the Global Precipitation Climatology Project (GPCP) rainfall observations). Our study also examines climate change simulations for the 21 st century which predict a doubling of atmospheric $\mathrm{CO}_{2}$ concentrations by 2100 (Meehl et al. 2007). When combined with ocean models and forced by projected trends in greenhouse gasses and aerosols, climate simulations can be used to examine the impact due to anthropogenic emissions into the atmosphere. This study examines 28 simulations from a standard emission scenario-the Special Report on Emissions Scenarios, SRESA1B. Individual simulations were weighted in such a way as to give each model an equal influence.

\section{Methods}

This section describes the approach taken by our regional food balance trend analysis, analysis of climate change scenarios and detailed analyses of Eastern African food security projections.

\section{Regional food balance projections}

One basic tenet of our work is that food availability plays a critical and increasing role in food security. Following the UN's Food and Agriculture Organization's division of the world into 18 regions, ${ }^{2}$ and using 1961-2007 data on total cereal yields, harvested area and total population, one can write a simple equation describing per capita cereal production $(c,[\mathrm{~kg}$ per person per year]) in terms of total

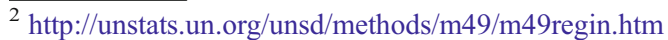


Table 1 Sources of agricultural, social and climate data used in this analysis

\begin{tabular}{|c|c|c|c|}
\hline Parameter & $\begin{array}{l}\text { Observed (o) } \\
\text { Predicted (p) }\end{array}$ & Time period & Source \\
\hline Cereal production statistics ${ }^{\mathrm{a}}$ & o & $1961-2007$ & $\begin{array}{l}\text { Food and Agriculture Organisation } \\
\text { http://faostat.fao.org/ }\end{array}$ \\
\hline Population data $^{\mathrm{b}}$ & $o \& p$ & $1960-2050$ & $\begin{array}{l}\text { United Nations Population Division } \\
\text { http://www.un.org/esa/population/unpop.htm }\end{array}$ \\
\hline Annual food aid totals ${ }^{c}$ & o & $1979-2005$ & $\begin{array}{l}\text { World Food Programme } \\
\text { http://www.wfp.org/ }\end{array}$ \\
\hline Seasonal Rainfall ${ }^{\mathrm{d}}$ & o & $1979-2007$ & $\begin{array}{l}\text { Global Precipitation Climatology Project } \\
\text { http://www.gewex.org/gpcp.html }\end{array}$ \\
\hline $20^{\text {th }}$ and $21^{\text {st }}$ Century rainfall simulations & $\mathrm{p}$ & $1950-2100$ & $\begin{array}{l}\text { Program for Climate Model Diagnosis } \\
\text { and Intercomparison } \\
\text { http://www-pcmdi.llnl.gov/ }\end{array}$ \\
\hline
\end{tabular}

${ }^{a}$ United Nations Food and Agricultural Organisation (FAO) yield, harvested area, seed and fertilizer statistics. These data have been pooled by commodity to include all cereal crops

${ }^{\mathrm{b}}$ United Nations World Population Division mid-level population estimates and projections

${ }^{\mathrm{c}}$ Total country level international food aid (food shipments plus cash subsidies), obtained from the FAO database

${ }^{\mathrm{d}}$ Combined gauge and satellite rainfall estimates, totaled over three-month seasons

e 20th and 21st climate change rainfall simulations produced by ten different global climate models

Table 2 Number of 20th Century $^{\mathrm{a}}(1980-2000) \& 21$ st Century ${ }^{\mathrm{b}}$ (2000-2100) simulations used in this study. These model simulations are produced by premier climate modeling groups $^{\mathrm{c}}$ in the United States, Europe and Asia

\begin{tabular}{lcc}
\hline Models & $\begin{array}{c}\text { 20th Century } \\
(1980-2000)\end{array}$ & $\begin{array}{c}\text { 21st Century } \\
(2000-2100)\end{array}$ \\
\hline GFDL CM 2.1 & 1 & 2 \\
GISS ER & 4 & 2 \\
IAP FGOALS & 3 & 3 \\
IPSL CM4 & 6 & 1 \\
MIROC3.2 Hi Res & 1 & 1 \\
MIROC3.2 Med Res & 3 & 3 \\
MPI ECHAM5 & 3 & 3 \\
MRI CGCM 2.3.2a & 1 & 5 \\
NCAR CCSM 3.0 & 1 & 7 \\
UKMO HADGEM1 & 1 & 1 \\
\hline
\end{tabular}

${ }^{a}$ The 20th Century simulations are based on observed sea surface temperature and atmospheric aerosol and greenhouse gas patterns, and have been drawn from the Atmospheric Model Intercomparison Project (AMIP) experiment

${ }^{\mathrm{b}}$ The 21 st Century simulations are based on predicted a $\mathrm{CO}_{2}$ doubling scenario (SRESA1B) provided by the IPCC. These 21st Century climate change simulations are drawn from the World Climate Research Program's Coupled Model Intercomparison Project phase 3 (CMIP3) multi-model dataset (Meehl et al. 2007)

${ }^{\mathrm{c}}$ Simulated 20th and 21st Century precipitation fields are drawn from multi-model ensembles of numerical weather predictions obtained from the Programme for Climate Model Diagnostics and Intercomparison. Full details about these models are available at http://wwwpcmdi.llnl.gov/projects/cmip/Table.php harvested area ( $a$,[hectares]), total population ( $n$, [people]) and total annual cereal yield ( $y,[\mathrm{~kg}$ per ha per year] $)$.

$c=(a / n) y$

This is a coarse metric that clearly ignores many important food security variables related to nutrition, access, trade, vulnerability, pastoral livelihoods, etc. (Davis et al. 2001; Devereux and Maxwell 2001). Nonetheless, per capita cereal production is an important indicator of food availability, especially in large landlocked regions with large agrarian populations, a restriction that applies to most of Africa, Asia, and South America. This study examines FAO statistics averaged over very large multi-national regions and this tends to diminish the relative impact of cross-border trade. Another advantage of this approach is transparency. Trends in per capita harvested area and yield can be analyzed and their relationship to per capita agricultural production diagnosed, revealing shifts in agricultural production and baseline vulnerability.

Conceptually, per capita production is influenced by negative and positive trends (Fig. 1); per capita harvested area declines while yields increase. Since 1961, in almost all regions of the world, the population $(n)$ has grown faster than the harvested area (a), so that the per capita planted area has decreased with time. Per capita harvested area thus represents the interaction of finite environmental resources with an expanding population. Other related factors, such as land degradation and soil nutrient depletion, are likely to change with time in the same way (Blaikie and Brookfield 1987). 


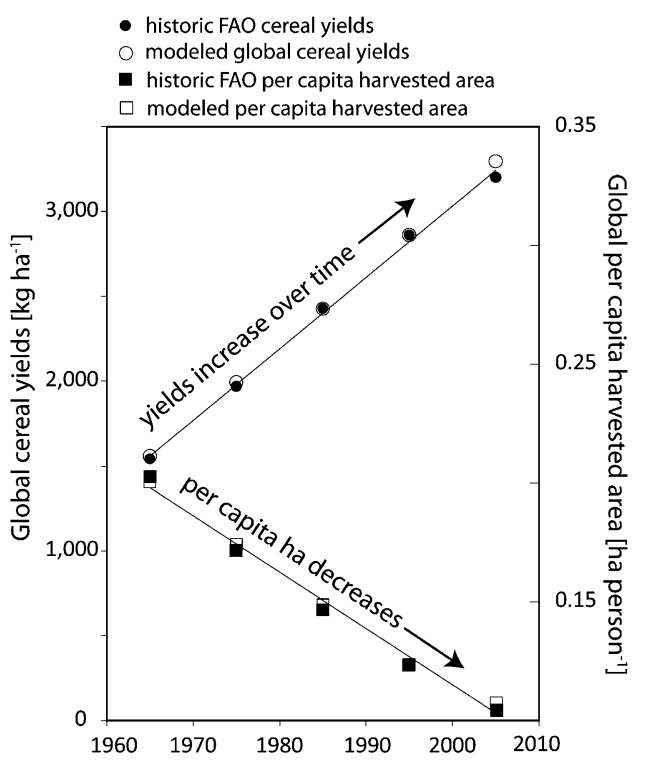

Fig. 1 Observed (FAO data) and modeled global cereal trends in yields and per capita harvested area averaged by decades. Modeled global cereal yields (open circles) fit observed yields (closed circles) very well. Similarly, modeled per per capita harvested area decreases (open boxes) give a good fit with observed data (closed boxes). Extrapolation of the trends are used in this paper to predict future outcomes

Yield trends, on the other hand, reflect increases in human knowledge, innovation, social and economic organization, as well as the ability and willingness to invest in improving agricultural production (Lo and Sene 1989; Watts 1989; Turner et al. 1993). Yield trends everywhere in the world have been positive over the past 50 years (Cassman et al. 2003). Together, per capita harvested area and yield trends describe the direction of per capita cereal production, one major determinant of food security.

Our focus is not on identifying individual food crises but on exploring slow changes in agricultural sustainability. Therefore, study uses 10 year averages of $a / n$ and $y$ for the 1960s, 1970s, 1980s, 1990s, and 2000-2008. Denoting trends with over-arrows, approximate tendencies in per capita cereal can be expressed as a function of time.

$\vec{c}=\overrightarrow{(a / n)} \vec{y}$

where $\ln \overrightarrow{(a / n)}=b_{0}+b_{1} \ln ($ Year $)$

and $\vec{y}=b_{2}+b_{3}$ Year

Trends in per capita cereal production are a function of trends in per capita harvested area and yield (Eqs. 2, 3 and 4). Since fitting linear trends to the 10 year per capita harvested area data produced negative projections for some regions (suggesting an impossible situation where the harvested area was less than zero), log-linear trend functions were fitted to the regional 10 year per capita harvested area data (Eq. 3). Linear trends were used to model yield data (Eq. 4).

The four parameter-models described by Eqs. 2, 3 and 4 were fitted individually to 18 large multi-national regions over the 1960s-2008 time period. At regional-decadal scales, the individual models performed well with typical R-squared values of 0.9 . While simple, this statistical framework is able to describe a large portion (84\%) of the regional-decadal per capita production variations and corresponds well with observed global variations (Fig. 1). If we assume continuity of these linear trends, we can project regional per capita production values into the first half of the 21 st century. The analysis also highlights the fact that population, yield, and harvested area trends tend to predominate over climate factors in determining production variations over time.

To better understand the human impacts of shifting relationships between population and cereal production, we define a 'theoretical population without food' or $p$.

$p=[($ ay $)-(\mathrm{ng})] \mathrm{g}^{-1}$

In this equation, $\mathrm{p}$ is the theoretical population without food, measured in units of people, (ay) is annual cereal production (yield times area) [kg per year], $\mathrm{n}$ is the number of people and $\mathrm{g}$ is the annual grain requirement per person $[\mathrm{kg}$ per person per year]. In practice, $g$ varies substantially between cultures and livelihood groups. This study assumes a caloric requirement of 1,900 calories/day and a typical caloric content of 3,600 calories per kilogram of grain. This leads to an annual grain requirement, in theory, of $190 \mathrm{~kg}$. This calculation presumes a perfect distribution of grain, and no use of cereal for biofuels, livestock, alcohol or other purpose (Cassman 2007). On the other hand, it also ignores imports and other sources of nutrition. While only an approximation of food availability, Eq. 5 provides a means of estimating the magnitude of cereal deficits and surpluses. Regions experiencing large cereal deficits may have theoretical food balances with large negative values, indicating that millions of people may experience food shortages. On the other hand, some regions may have large grain surpluses, theoretically able to support millions of people. It is important to note that this calculation assumes a low baseline consumption rate.

\section{Climate change rainfall projections}

Because global climate models represent terrestrial rainfall poorly, it is often preferable to focus on large scale climate features that they represent well. Two such patterns are rainfall over the central Indian Ocean (IO) and the 1st principal component $(\mathrm{PC} 1)$ of global seasonal precipitation. This study describes these indicators, evaluates how they 
might change during the early 21 st century, and uses these changes to predict 2050 changes in mean rainfall.

The central Indian Ocean is a critical influence on drought along the eastern seaboard of Africa (Verdin et al. 2005). Greenhouse gas emissions have increased Indian Ocean temperature (Funk et al. 2008); this warming disrupts onshore moisture transport into South and East Africa, substantially reducing main season rainfall, especially during the 6 months between December and May. This analysis uses seasonal March-April-May (MAM), June-July-August (JJA), September-October-November (SON), and DecemberJanuary-February (DJF) rainfall totals averaged between 0 $15^{\circ} \mathrm{S}$ and $60-90^{\circ} \mathrm{E}$ to represent Indian Ocean warming. We refer to this indicator as 'IO,' for 'Indian Ocean'.

Variations in the tropical Pacific Ocean also influence global changes in precipitation. The most important time variations of global rainfall anomalies can be summarized by their 'principal components', or PCs, which are time series designed to succinctly summarize the underlying data. The first principal component of global rainfall (PC1) is strongly correlated with El Niño and tropical SSTs in the central-eastern tropical Pacific.

This study examines the IO and PC1s from a large set of climate change simulations (Table 2). Using historical observations, we then statistically relate variations in our two indicators to variations in observed terrestrial rainfall. These hybrid dynamic-statistical models rely on the climate models to predict the changing behavior of large scale climate features and on statistics to interpret the local implications of these changes. Two hybrid statisticaldynamic reformulations are presented: a global reformulation (Brown and Funk 2008) and a higher resolution analysis focused on east and South Africa. This hybrid statistical-dynamic technique is quite distinct from the evaluations provided by the Intergovernmental Panel on Climate Change (IPCC: Solomon et al. 2007). Our statistical downscaling approach tends to identify declines in monsoonal precipitation in Asia and East Africa, where the IPCC simulations tend to suggest increasing rainfall.

\section{Detailed analysis of Eastern African food aid tendencies}

This section presents a more detailed discussion of food security tendencies in Eastern and Southern Africa. Specifically, we analyze Eritrea, Ethiopia, Kenya, Uganda, Rwanda, Burundi, Tanzania, Zambia, Malawi, Mozambique, Zimbabwe, Swaziland and Lesotho. This region broadly aligns with the FAO's 'Eastern Africa' region (FAO 2007). Climatically, this collection of nations along the eastern edge

\footnotetext{
${ }^{3}$ Please note that this indicator is distinct from the Indian Ocean dipole, which compares sea surface temperature (SST) anomalies in the southeastern and northwestern tropical Indian Ocean.
}

of Africa falls into two groups. The southern states experience a single rainfall maximum during DecemberFebruary (DJF). The northern states, in the Greater Horn of Africa, typically experience two rainfall maxima: in MarchMay (MAM) and in September-November (SON). Ethiopia and Eritrea have a maximum in June-August (JJA). We have included Tanzania within Southern Africa because DJF is the most agriculturally productive quarter.

The objective of the analysis is to estimate the relationship between main season rainfall, agricultural statistics, population figures and World Food Program food aid totals for each of these nations over the time period 1979-present. Log-linear empirical models of national annual cereal production were created by regressing historical FAO production data against main season rainfall, harvested area, and seed and fertilizer inputs.

$p=b_{1} r \cdot b_{2} a \cdot b_{3} s \cdot b_{4} f$

Where $r$ is main season rainfall expressed as a percent of the historical mean, $a$ is harvested area, $s$ is input seed, and $f$ represents fertilizer use; $\mathrm{p}$ is total cereal production $[\mathrm{kg}]$, and $b_{1 \ldots 4}$ are coefficients determined by regression between the natural logs of $p, r, a, s$, and $f$. Seed and fertilizer values obtained from FAO are measured in kg per year. Combining this equation with Eq. 1 allows us to separate the primary environmental variation (rainfall) from 'structural' components of national per capita cereal production.

$c=b_{1} r\left(b_{2} a \cdot b_{3} s \cdot b_{4} f \cdot n^{-1}\right)$

In this equation $\mathrm{c}$ is per capita cereal production $[\mathrm{kg}$ per person per year]. This equation is similar to Eq. 1, but more explicit. The key factors determining yields (seed, fertilizer and rainfall) are now included. This gives us a quantitative means to assess the impacts of drought and changes in seed and fertilizer use. We can further separate Eq. 7 into environmental (e) and human (h) components.

$c=e h$

where $e=b_{1} r$

and $h=\left(b_{2} a \cdot b_{3} s \cdot b_{4} f \cdot n^{-1}\right)$

The environmental component includes interannual variation in weather, plus long-term variations that may be associated with climate change. The human component includes a combination of population $(n)$ and large-scale agricultural factors (harvested area $a$, seed use $s$, and fertilizer use $f$, as per capita demand based on population. This combination of factors $(h)$ is referred to as 'per capita agricultural capacity'. Typically, all of these terms tend to trend strongly and vary less than rainfall on interannual time scales. Thus, agricultural capacity trends tend to dominate food security variations on 10 year time scales. 
Rainfall tends to vary substantially from year to year, producing variations in production about a baseline.

For Eastern, Western, and Southern Africa, the inverse of national per capita cereal production (i.e., a food deficit or imbalance) is strongly related to regional, 10 year variations in World Food Program (WFP) food aid $\left(\mathrm{R}^{2}=0.87\right.$, Funk et al. 2008). Area harvested trends, seeds, fertilizer and population may be placed in Eq. 8 to assess the potential impacts these tendencies have on baseline agricultural capacity. The relative impact of changes in rainfall versus structural elements may also be assessed using Eq. 8 . Additionally, Eq. 8 implies a potential for multiplicative impacts in areas experiencing both drought and decreasing per capita agricultural capacity.

\section{Results}

Global food balance analysis

Between 1961 and 1986, global total cereal yield increased by $89 \%$, harvested area expanded by $11 \%$ and global per capita cereal production increased enormously, with a maximum in about 1986 (Fig. 2). Population, meanwhile, grew by $60 \%$ over those 25 years, resulting in an increase in per capita cereal production from 284 to $372 \mathrm{~kg}$ of grain per person per year. The last 21 years (1987-2007) have seen slower population growth (34\% increase) accompanied by slower yield improvements (31\% increase) and a $2 \%$ reduction in the total area harvested. Surprisingly, over this period according to FAO and UN data, per capita harvested area, fertilizer and seed use have all declined by $20-30 \%$ (Fig. 2). Presumably, higher yielding seeds, double cropping of rice, irrigation and more effective farming techniques have made up for lower per capita inputs. Per capita production is now about $350 \mathrm{~kg}$ of cereal per person per year, 6\% less than the 1986 maximum.

The relative stabilization of global per capita production hides the increased use of cereals for biofuels, alcohol and meat production, as well as significant variations between regions. Population growth rates vary tremendously geographically (Table 3). Four regions have more than doubled their population since 1980: Eastern Africa, Western Africa, Middle Africa and Western Asia. Central America, Southern America, Northern Africa, Southern Africa, Southern Asia, and Southeastern Asia have seen their populations increase by more than $50 \%$. Since 1980 , two out of every three people born now live in Asia. Another one out of four lives in Africa.

Across most of Africa, harvested area has increased substantially more than yields (Funk et al. 2008). In Eastern Africa, for example, yields have only increased by $25 \%$ since 1980 , while harvested area increased by $55 \%$. In

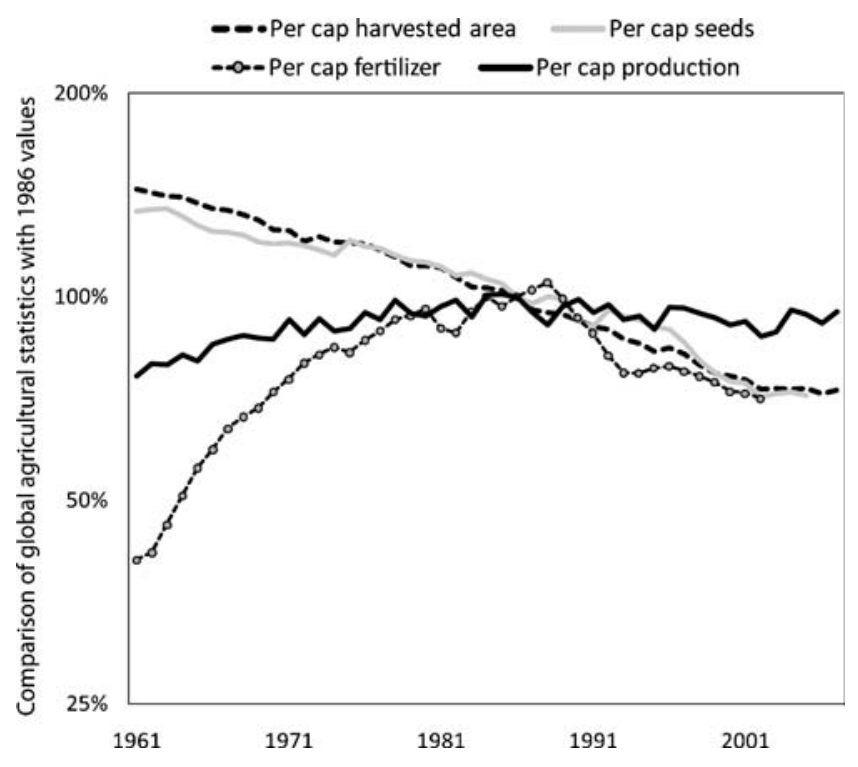

Fig. 2 Global per capita cereal production statistics, expressed as percentages of a 1986 baseline. Data were obtained from FAO. Population figures are based on estimates from the United Nations. Total cereal production divided by the Earth's population (solid black line) has stagnated since the mid-1980s. Since 1961, the total area devoted to cereal farming has increased, but more slowly than population growth leading to a fairly linear decline in per capita harvested area (dashed line). The total amount of global seed grain tracks closely with harvested area, and per capita seed use (grey line) follows a similar downward linear trend. Total per capita fertilizer use follows a parabolic trend, peaking the mid-1980s

Western Africa yields increased by $42 \%$ while harvested area increased by $127 \%$. Yields, per capita harvested area and production remain very low. Across much of the rest of the world, harvested areas have remained fairly steady and yields have been the primary driver of agricultural growth. Our evaluation of FAO statistics shows that Southern America, Northern America, Eastern, Southern and Southeastern Asia have experienced greater than $70 \%$ increases in yields since 1980. Today, huge regional disparities in yields remain the norm. In 2007, cereal yields varied by almost $600 \%$, from $\sim 1,000 \mathrm{~kg} \mathrm{ha}^{-1}$ in Middle Africa, to more than $5,000 \mathrm{~kg} \mathrm{ha}^{-1}$ in Northern America, Eastern Asia, and Europe. ${ }^{4}$

Given that global and regional tendencies in per capita harvested area and yields appear fairly predictable $\left(\mathrm{R}^{2}>0.8\right)$ on 10 year scales (Fig. 1), we may plausibly use the observed trends to project to 2030. Table 4 presents the anticipated 2007 to 2030 changes, expressed as $\mathrm{kg}$ of cereals per person per year, and as percent changes compared to 2007. Figure 3 shows the historical and projected per capita cereal production for selected regions. Globally, a return to per capita production of the late 1960s, when per capita production was near $327 \mathrm{~kg}$ per person,

\footnotetext{
${ }^{4}$ Note that this study uses FAO cereal yields data. The specific commodities will vary substantially by region.
} 
Table 3 Relevant agricultural statistics for 2007 obtained from the FAO. Unless international trade and aid can make up the difference, areas with theoretical food balance deficits will face systematic food shortages. The magnitude of these shortages can be evaluated by looking at the food balance deficits expressed as percentages of the total population. With some exceptions, regions with the largest population increases over the past 27 years also have the largest per capita food deficits

\begin{tabular}{|c|c|c|c|c|c|c|c|}
\hline & \multirow{2}{*}{$\begin{array}{l}\text { Population }^{\mathrm{a}} \\
\text { Millions } \\
\text { of people }\end{array}$} & \multirow{2}{*}{$\begin{array}{l}\text { Yield }^{\mathrm{b}} \\
\mathrm{kg} \mathrm{ha}^{-1}\end{array}$} & \multirow{2}{*}{$\begin{array}{l}\text { Per capita Harvested } \\
\text { Area }^{\text {c }} \\
\text { ha person }\end{array}$} & \multirow{2}{*}{$\begin{array}{l}\text { Per capita } \\
\text { Production }^{\mathrm{d}} \\
\text { kg person }^{-1}\end{array}$} & \multicolumn{2}{|c|}{$\begin{array}{l}\text { Theoretical Food } \\
\text { Balance [millions] }\end{array}$} & \multirow{2}{*}{$\begin{array}{l}\% \text { change in } \\
\text { population }^{f} \\
{[\%]}\end{array}$} \\
\hline & & & & & $\begin{array}{l}\text { millions } \\
\text { of people }\end{array}$ & {$[\%]^{\mathrm{f}}$} & \\
\hline Regions & 2007 & 2007 & 2007 & 2007 & 2007 & 2007 & 1980-2007 \\
\hline World & 6,612 & 3,347 & 0.11 & 354 & 5,548 & & 49 \\
\hline Eastern Africa & 302 & 1,482 & 0.09 & 131 & -96 & -32 & 107 \\
\hline Middle Africa & 116 & 967 & 0.06 & 62 & -79 & -68 & 113 \\
\hline Northern Africa & 198 & 1,725 & 0.11 & 190 & -3 & -1 & 77 \\
\hline Southern Africa & 54 & 2,466 & 0.07 & 182 & -3 & -6 & 63 \\
\hline Western Africa & 276 & 1,165 & 0.16 & 189 & -5 & -2 & 107 \\
\hline N. America & 337 & 5,913 & 0.23 & 1374 & 2,066 & & 32 \\
\hline Cent. America & 151 & 2,893 & 0.08 & 243 & 40 & & 67 \\
\hline Caribbean & 40 & 2,201 & 0.02 & 51 & -29 & -73 & 36 \\
\hline South America & 385 & 3,704 & 0.09 & 349 & 314 & & 59 \\
\hline Central Asia & 59 & 1,696 & 0.32 & 541 & na & & 11 \\
\hline Eastern Asia & 1,541 & 5,418 & 0.06 & 314 & 967 & & 31 \\
\hline Southern Asia & 1,603 & 2,645 & 0.09 & 231 & 323 & & 71 \\
\hline S-Eastern Asia & 570 & 3,756 & 0.10 & 368 & 518 & & 59 \\
\hline Western Asia & 223 & 1,985 & 0.10 & 204 & 13 & & 121 \\
\hline Eastern Europe & 295 & 2,228 & 0.27 & 606 & 632 & & -18 \\
\hline N. Europe & 96 & 5,149 & 0.09 & 472 & 140 & & 18 \\
\hline S. Europe & 146 & 4,147 & 0.10 & 416 & 169 & & 6 \\
\hline W. Europe & 187 & 6,419 & 0.09 & 594 & 389 & & 9 \\
\hline Oceania & 34 & 1,221 & 0.06 & 68 & 85 & & 49 \\
\hline
\end{tabular}

${ }^{\text {a }} \mathrm{UN}$ population estimates for 2007

${ }^{b}$ The total FAO cereal yield for 2007 for the region

${ }^{\mathrm{c}}$ The ratio of the total cereals harvested area and population

${ }^{\mathrm{d}}$ Per capita production, or the ratio of the total cereal production and population

${ }^{\mathrm{e}}$ The theoretical food balance defined by Eq. 5. This is the number of unfed people assuming a caloric cereals requirement of $190 \mathrm{~kg}$ per person per year

${ }^{\mathrm{f}}$ Food balance deficit expressed as percentages of the total population in 2007

g. The last column shows recent population increases, expressed percent of the 1980 population

appears likely. Eastern Asia may return to 1980s production levels (near $300 \mathrm{~kg}$ person ${ }^{-1}$ ) and Southern Asia to $1960 \mathrm{~s}$ levels (near $200 \mathrm{~kg}$ person ${ }^{-1}$ ). Declines in heavily populated Asia could re-expose millions of people to chronic undernourishment. ${ }^{5}$ Central and Southern America may experience $18-20 \%$ declines in per capita cereal production levels. Eastern and Middle Africa, however, may be affected most, with more than $30 \%$ reductions in already

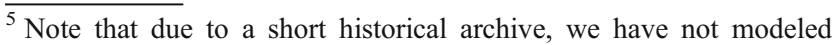
central Asia (Kazakhstan, Kyrgyzstan, Tajikistan, Turkmenistan, and Uzbekistan). This region is likely to exhibit similar trends in food security, potentially further exacerbated by increasing temperatures and water scarcity.
}

low per capita cereal production levels, with Eastern Africa changing from $131 \mathrm{~kg}$ per year in 2007 to $84 \mathrm{~kg}$ per person per year in 2030. United Nations (UN) projections suggest that the population of Eastern Africa will increase by 191 million people by 2030 - a net increase second only to Southern Asia.

While imprecise, it is instructive to evaluate simple food balance equations, examining the number of people who could be reasonably supported by the anticipated levels of grain production (Table 4). We do this by calculating the theoretical population without food (Eq. 5). Globally, the 2030 food balance estimates suggest that as now, we will still have enough grain to maintain our human population, 
Table 4 Global and regional projections of per capita cereal production (Eq. 1) and theoretical food balance (Eq. 5) statistics. These values were based on 2030 estimates of yields and per capita harvested area. Overall, and on average for the world, there will be $48 \mathrm{~kg}$ less of cereal production per person per year in 2030, a $14 \%$ reduction over the $354 \mathrm{~kg}$ per person produced in 2007

\begin{tabular}{|c|c|c|c|c|}
\hline \multirow[b]{2}{*}{ Units } & \multirow{2}{*}{$\begin{array}{l}2030 \text { per capita cereal production }{ }^{\mathrm{a}} \\
{\left[\mathrm{kg} \mathrm{person}^{-1}\right]}\end{array}$} & \multicolumn{2}{|c|}{ Change in annual per capita production (2030-2007) } & \multirow{2}{*}{ 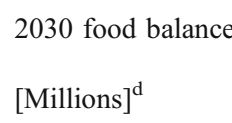 } \\
\hline & & {$\left[\mathrm{kg} \text { person }^{-1}\right]^{\mathrm{b}}$} & {$[\%]^{\mathrm{c}}$} & \\
\hline World & 306 & -48 & -14 & 4,833 \\
\hline Eastern Africa & 84 & -47 & -36 & -277 \\
\hline Middle Africa & 38 & -24 & -38 & -166 \\
\hline Northern Africa & 180 & -10 & -5 & -18 \\
\hline Southern Africa & 189 & 8 & 4 & -1 \\
\hline Western Africa & 166 & -23 & -12 & -61 \\
\hline N. America & 1,236 & -138 & -10 & 2,168 \\
\hline Cent. America & 199 & -44 & -18 & 6 \\
\hline Caribbean & 47 & -4 & -9 & -34 \\
\hline South America & 273 & -76 & -22 & 203 \\
\hline Eastern Asia & 276 & -37 & -12 & 716 \\
\hline Southern Asia & 193 & -38 & -17 & 5 \\
\hline S-Eastern Asia & 356 & -12 & -3 & 594 \\
\hline Western Asia & 160 & -44 & -22 & -54 \\
\hline Eastern Europe & 542 & -64 & -11 & 468 \\
\hline N. Europe & 618 & 146 & 31 & 227 \\
\hline S. Europe & 396 & -20 & -5 & 145 \\
\hline W. Europe & 771 & 176 & 30 & 569 \\
\hline Oceania & 1,158 & 484 & 72 & 213 \\
\hline
\end{tabular}

${ }^{\text {a }} 2030$ yields and per capita harvested area were estimated based on 1960-2007 trends (Eqs. 2, 3, 4 and 5), and used to derive estimates of 2030 per capita cereal production (Eq. 1)

${ }^{\mathrm{b}}$ The difference, in kilograms per person, between projected 2030 and observed 2007 per capita cereal production

${ }^{\mathrm{c}}$ The difference, expressed as a percentage change, between projected 2030 and observed 2007 per capita cereal production

${ }^{\mathrm{d}}$ Theoretical food balance (Eq. 2) for 2030, expressed in millions of people, based on an annual cereal requirement of $190 \mathrm{~kg}^{\mathrm{p}} \mathrm{person}{ }^{-1} \mathrm{year}^{-1}$

albeit at a low baseline value of 1,900 calories a day. This estimate, however, does not take into account grain consumption associated with livestock production, biofuels or industrial applications.

Most of the production increases supporting these surpluses may occur in Eastern and Southern Asia and Northern America, where our modeling suggests $47 \%$ and $28 \%$ of new production will occur as a consequence of 25 to $35 \%$ increases in yields. Our projected yields in Eastern Asia and Northern America reach 7,500 kg ha ${ }^{-1}$. Yields of this magnitude assume further innovation and increasing petrochemical inputs, and may not be technically feasible (Cassman et al. 2003). However, regionally, a continuation of recent trends that include vast disparities of access to food will probably expose hundreds of millions more people to chronic food insecurity, even if increasing cereal demands as a result of biofuels and increased consumption are ignored.

With a 2030 population of about 2.1 billion, Southern Asia will face substantial food availability challenges. Our 2030 projections suggest a per capita cereal production of
$193 \mathrm{~kg}$ per person per year (Table 4). This value is slightly greater than our arbitrary subsistence threshold of 190 but substantially (38\%) less than the 2007 value of 231 . Hence, while our theoretical 'food balance' suggests sufficiency, real conditions will probably result in chronic food shortages for large segments of this diverse region who have negligible purchasing power. By 2050, our theoretical food balance (Eq. 5) suggests that regional cereal production might be adequate for only $90 \%$ of the population, leaving a shortfall equivalent to the amount required by 373 million people. Substantial water scarcity intensified by anthropogenic increases in air temperature and evaporation (Parry et al. 2007) will further hamper agricultural expansion. Central Asia appears likely to face challenges ${ }^{4}$ similar to those of Southern Asia.

Eastern and Western Africa, where cereal crops provide the majority of calories, will face substantial and increasing food security challenges. Per capita cereal production in Eastern Africa may decrease from a low $131 \mathrm{~kg}$ per person per year in 2007 to a very low $84 \mathrm{~kg}$ per person per year in 2030. This decline almost triples the theoretical food 


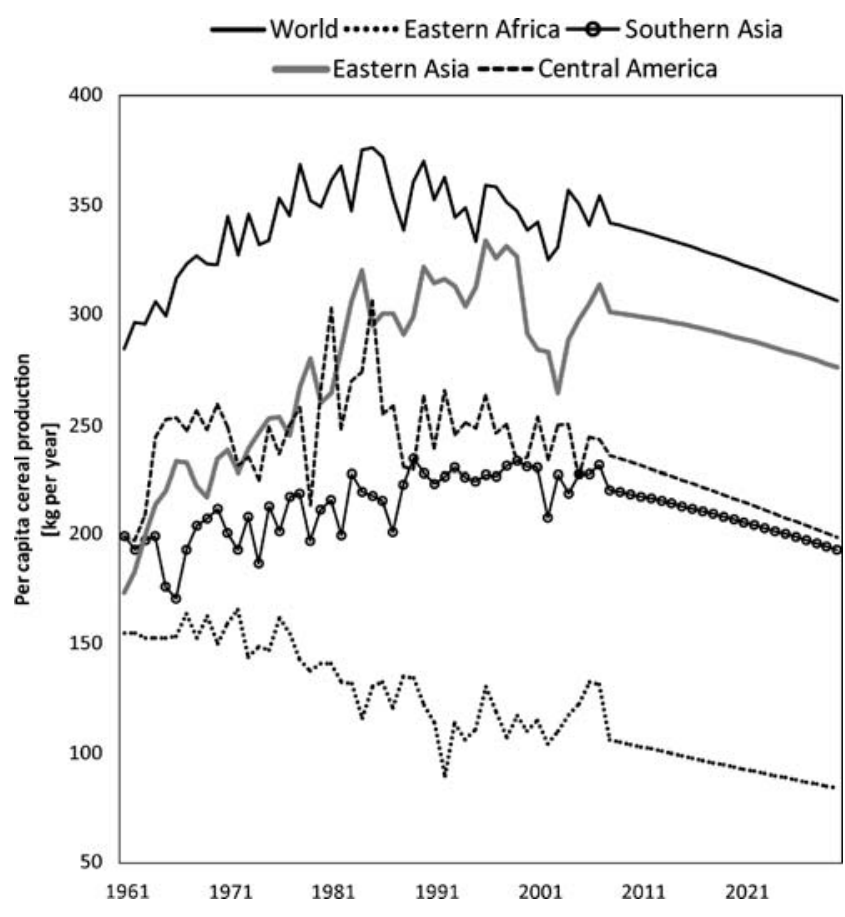

Fig. 3 Time-series of per capita cereal production for the world, Eastern Africa, Southern Asia, Eastern Asia, and Central America. Values beyond 2007 are projections

imbalance from -96 million in 2007 to -277 million people in 2030. This corresponds to $32 \%$ of the total population in 2007 and $56 \%$ of the population in 2030. Western Africa faces a similar, albeit more modest, decline in per capita production (from 189 to $166 \mathrm{~kg}$ per person per year). Our theoretical food balance suggests that this could expose about 61 million people, or $14 \%$ of the population to chronic food shortages.

This analysis suggests that Africa and Asia will experience continuing decreases in food availability and security. Rapidly growing populations and increasing temperature will place further demands on scarce water supplies. Biofuels and rising demand by the global middle class will probably compete for global production, raising prices and reducing food access for rural and urban poor. Eighty-eight percent of the 2007-2030 population growth will occur in African and Asian countries which will be strongly influenced climatically by the rapidly warming Indian and Pacific tropical Oceans (Funk et al. 2008; Brown and Funk 2008).

Climate change analysis

\section{Potential climate changes in the IO and PCl climate indicators}

What do global climate change models tell us about $21 \mathrm{st}$ century rainfall? The models (Table 2), on average, suggest increases in tropical rainfall over the Indian Ocean and tropical Pacific Ocean (Fig. 4). In these regions with very warm surface waters, there is a clear relationship between SSTs and tropical atmospheric dynamics. Future warming of the oceans appears likely to increase rainfall over the tropical Indian and Pacific basins. This increased oceanic rainfall will release large amounts of energy into the atmosphere, impacting global and regional circulations. These impacts may be quantified using the 21 st century climate change simulations to calculate the $\mathrm{PC} 1$ and IO climate indicators (see Section Climate change rainfall projections).

In general, the areas with increasing precipitation (blue areas in Fig. 4) correspond to the geographic footprint of both $\mathrm{PC} 1$ and IO, and the models examined suggest that both PC1 and IO will increase by 2050 (Fig. 5). The global (PC1) response, which corresponds strongly to warming in the central Pacific, appears to increase in all quarters. The IO warming appears much greater during March-April-May (MAM) and December-January-February (DJF) than JuneJuly-August (JJA) or September-October-November (SON). However, there is an inherent uncertainty in all these projections due to differences in model formulations, natural 10-year variations in the climate and the imperfect simulations of key processes, such as El Niño. To quantify this uncertainty the differences between the simulations can be examined and the $68 \%$ confidence intervals obtained from these differences evaluated (Fig. 5). In summary, the models appear to agree on substantial increases in the PC1 and IO indicators, implying associated changes in the Indian and Pacific Oceans circulations, but there is still a high level of uncertainty as to the size of the changes.

When using climate change simulations, it is important to realize how poorly the models used in the IPCC assessments represent rainfall over land. The average seasonal correlation between 1980-2000 observed and modeled rainfall was examined (Fig. 6a). Each grid box shows the correlation for the quarters (DJF, MAM, JJA, SON) with the highest mean rainfall. Multi-model ensemble estimates were made for each model, the correlations estimated, and then averaged across the models. In general, areas over the tropical oceans fit well with the climate models and have good correlations. Brown boxes denote areas where the IPCC models tend to perform very poorly, with correlations of less than 0.3. Dark green areas are reasonably skillful $(R>0.6)$. In the Indian and Pacific Oceans, these areas also tend to be areas with substantial increases in rainfall predicted (Fig. 4). However, over almost all land areas these evaluations suggest very small correlation coefficients. This low level of skill makes analysis of simulations of 'raw' climate change rainfall problematic. Since the IPCC models tend to perform poorly over land and reasonably well over the oceans, this study adopted an alternative approach, based on hybrid-dynamicstatistical reformulations. 
Fig. 4 Predicted precipitation changes for the 21 st century, based on a large set of climate change scenarios (See Table 2). The outputs from these simulations were averaged for each quarter (March-April-May: A, June-July-August: B,

September-October-November: C, December-January-February: D). Trends for the time period 2000-2100 were then calculated and plotted. The model simulation shows substantial increases in rainfall over the oceans

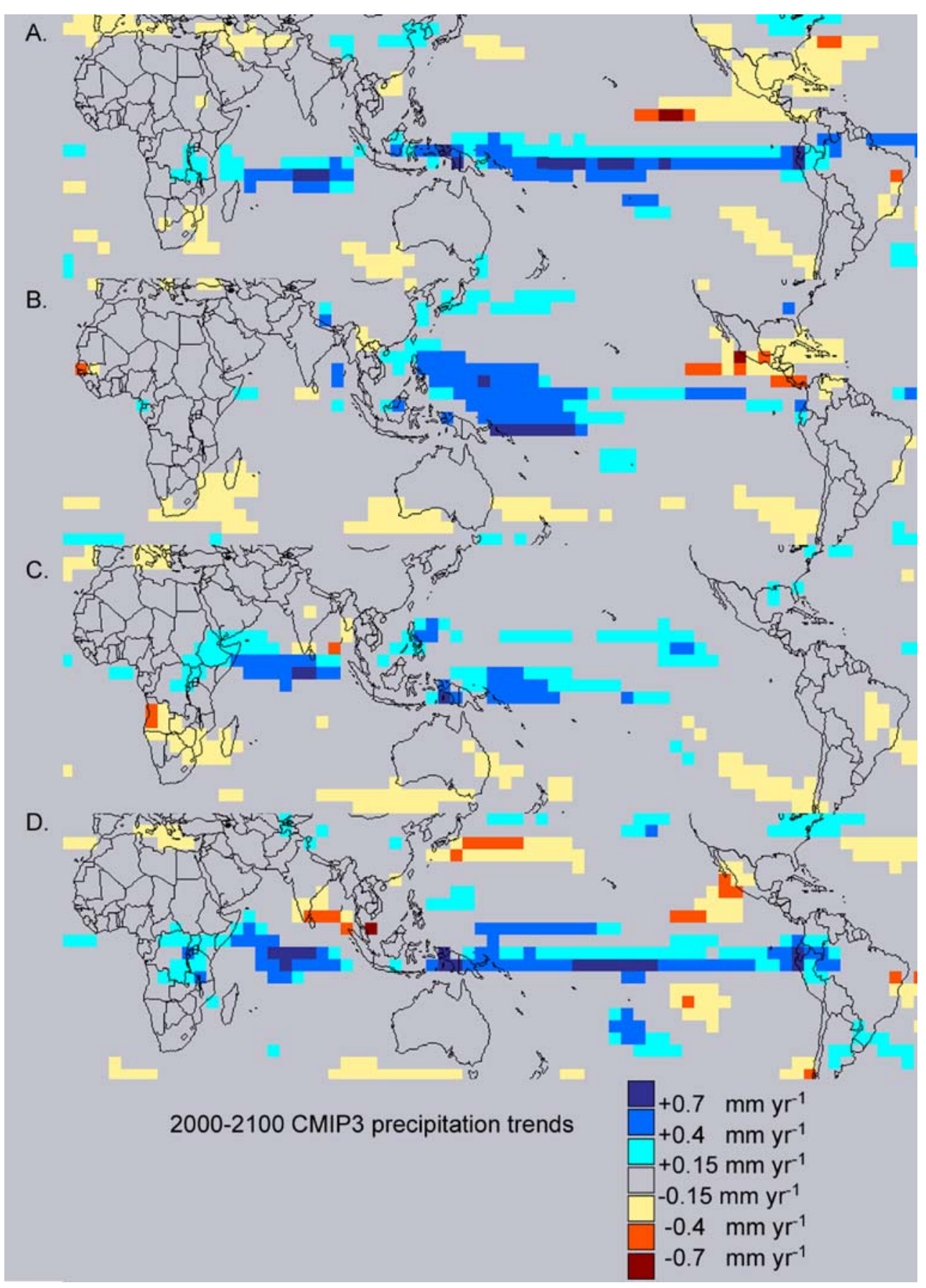

Hybrid dynamic-statistical reformulations of 21st century climate change simulations

Hybrid dynamic-statistical reformulations (Funk et al. 2008; Brown and Funk 2008) provide one potential way to overcome the limitations of global climate models. Instead of using the climate model precipitation directly, this analysis uses regression (based on historical data) to relate changes at some location to large scale climate indicators (such as $\mathrm{PC} 1$ or IO, Fig. 5). This is especially useful when there is good evidence linking changes in tropical oceanic rainfall and SSTs to terrestrial rainfall (e.g. Funk et al. 2008). Precipitation reformulations (Brown and Funk 2008), based on the 1st and 2nd principal components of global precipitation (Fig. 6b) suggest that substantial rainfall declines may occur over Central America, northern South America, Africa, and parts of Southern Asia, and Australia.

For more detailed spatial analysis, regressions between African rainfall and PC1 and IO time-series may be used to 
Fig. 5 Summary of changes in precipitation predicted for 2050: global (PC1, $\mathrm{x}$-axis) and Indian Ocean (IO, y-axis).

All indicator time series have been standardized, with an expected mean of zero and standard deviation $(\sigma)$ of 1 . Thus a change of +1 would indicate a shift in the mean value equivalent to a standard deviation of 1 . The figure gives the anticipated seasonal 2050 change for a given quarter (March-April-May [MAM], December-January-February [DJF], June-July-August [JJA)] and September-OctoberNovember [SON]. The intermodel variation of the climate models is shown using lines indicating the $68 \%$ confidence interval

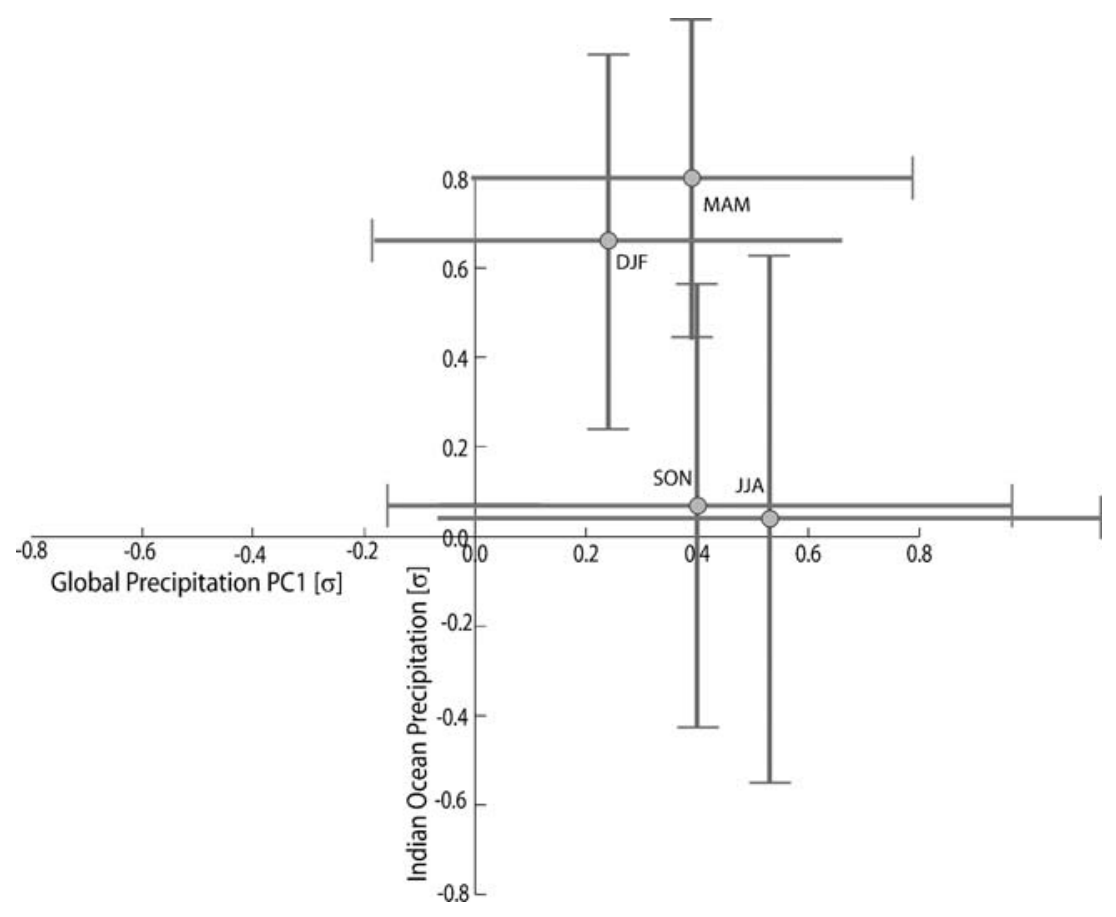

downscale anticipated 21 st century shifts in these climate forcings (Fig. 7). The season with the highest mean rainfall was selected (Fig. 7a). Regression equations linking PC1 and IO to the local rainfall were then estimated. For most areas, these models explained $40-70 \%$ of the variance. For parts of sub-tropical Eastern Africa and Southern Africa near the Indian Ocean, increasing IO and PC1 values are associated with increasing aridity, warm anomalies in the south-central Indian Ocean and moderate-to-strong El Nino Southern Oscillation (ENSO), typically associated with below normal MAM or DJF rainfall (Fig. 7b). These historical relationships, combined with projected increases in the IO and PC1 indicators (Fig. 5), suggest continued declines in rainfall across southern Ethiopia, Somalia, Kenya, northern Tanzania, southern Mozambique and southern Zimbabwe. While considerable uncertainty remains, it appears plausible, and even likely, that portions of Zimbabwe, Mozambique, Tanzania, Kenya, Somalia and southern Ethiopia may experience greenhouse gas induced rainfall reductions over the next 40 years. Therefore, if warming of the Pacific and Indian Ocean continues, as suggested by climate change models (Fig. 4), anthropogenic drought appears likely to impact one of the most food insecure regions of the world.

Our conclusions are generally in agreement with the most recent 4th IPCC finding that semiarid Africa may experience large-scale water stress and yield reductions by 2020 (Solomon et al. 2007). Our work, however, avoids the direct use of terrestrial precipitation simulations due to their low accuracy (Fig. 6a). Focusing on downscalings (Fig. 7) of climate forcing diagnostics (Fig. 5), however, suggests further drying, especially for Eastern Africa, where the IPCC report (Solomon et al. 2007) suggests that precipitation will increase. Future expansion of this work into Asia could help confirm the potential decline in the Asian monsoon suggested by our global reformulations (Fig. 6b).

Detailed African food security analysis

In Africa, the trends determining food security are complex. Selected agricultural, food aid and population statistics for 18 semiarid food insecure countries in Western Africa, Eastern Africa and the eastern part of Southern Africa (Table 5) include combined data for Ethiopia and Eritrea as they were united before 1993. Geographic variations between these three regions play a strong role in their level of agricultural self-sufficiency. In 2005, the Western African countries had, on average, three times as much harvested area as Eastern Africa (0.26 versus 0.08 ha person $\left.^{-1}\right)$. Per capita harvested areas for southeastern portions of Southern Africa are only slightly higher than those for Eastern Africa ( 0.10 ha per person ${ }^{-1}$ ). There are also considerable differences in per capita harvested area between the countries in each of these regions.

For these countries, harvested area largely determines national cereal production totals. ${ }^{6}$ Over the period 20012005 , the relatively food secure Sahelian countries ${ }^{7}$ have per

\footnotetext{
${ }^{6} \mathrm{R}^{2}=0.96$ for $1979-2005$ mean area vs. production totals for these 18 countries.

${ }^{7}$ Sparsely populated Mauritania and groundnut-dependent Senegal are not well modeled in this analysis structure.
} 
a. Average correlation between simulated and observed main season rainfall, 1980-2000

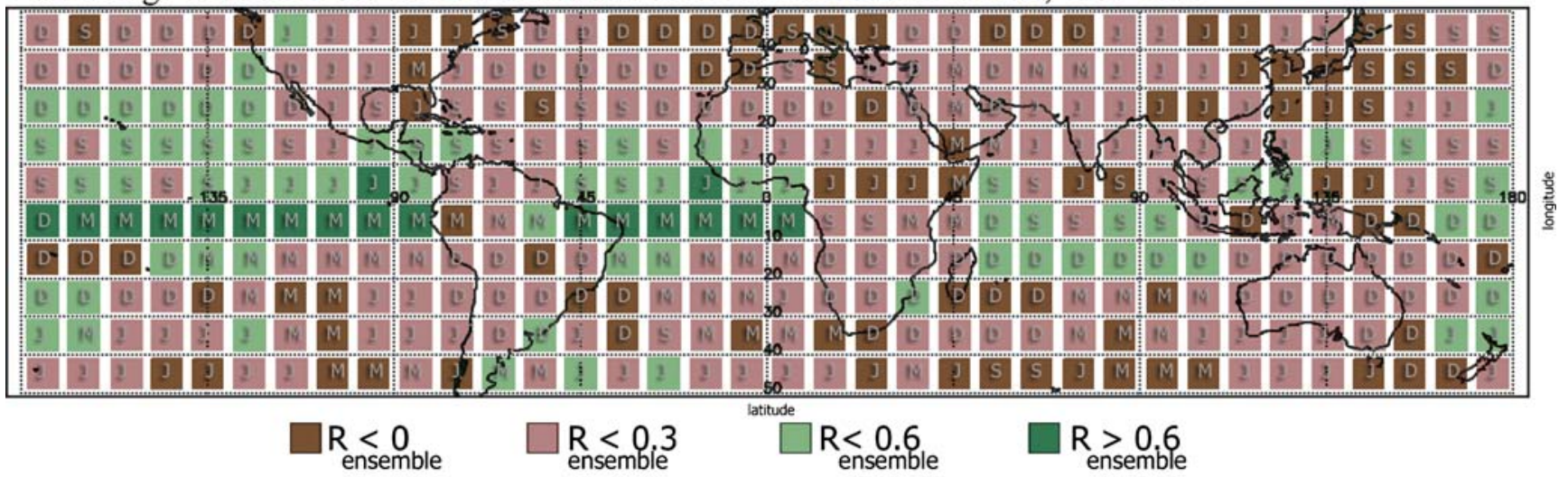

b. Statistical estimates of 2050 main season rainfall changes, expressed in standard deviations

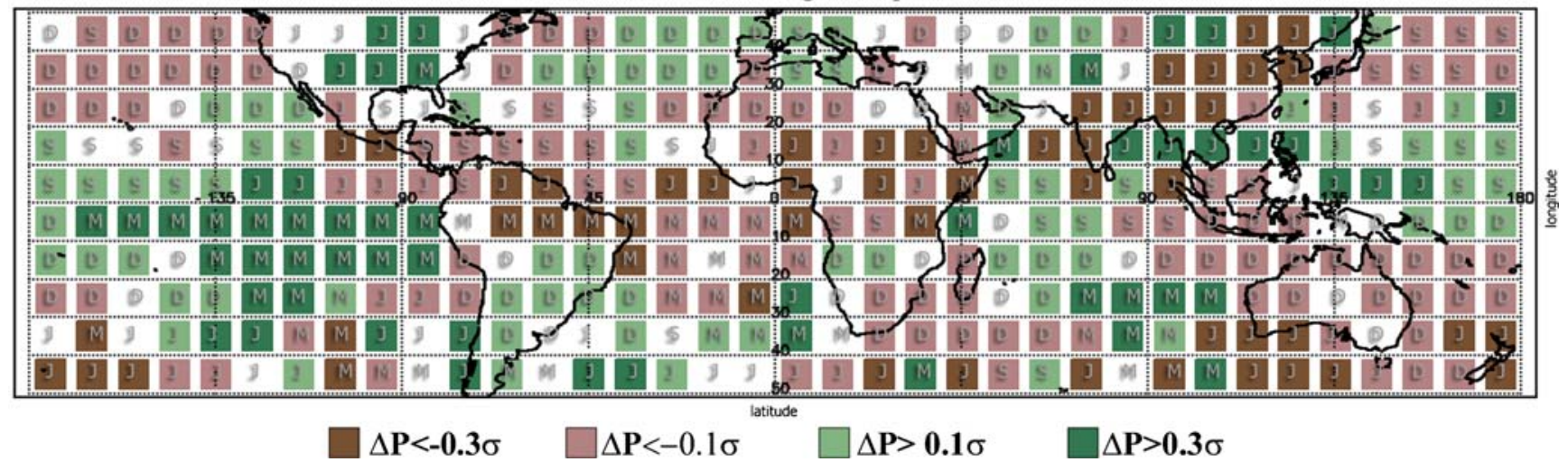

Fig. 6 The average correlation between the observed and modeled rainfall during the main rainfall season (a). These seasons are shown with letters, D denotes DJF, M = MAM, J = JJA, $\mathrm{S}=\mathrm{SON}$. The ensemble correlation, was estimated by calculating the correlation for each 20th century model simulation listed in Table 2 and then averaging. The yellow and brown boxes are areas in which the modeled rainfall is very inaccurate. The bottom panel (b) shows our estimates of 2050 rainfall changes $(\Delta \mathrm{P})$. These are changes in the main rainy season expressed in standard deviations and are based on the first two principal components of modeled 21 st century rainfall, assuming a universal $\mathrm{CO}_{2}$ doubling scenario. The light/dark brown boxes show a modest/considerable reduction in mean rainfall. Results in b reprinted from Brown \& Funk (2008), with the permission of AAAS

In these semiarid countries, a strong dependence on rainfed smallholder farming practices results in quasi-linear relationships between seasonal rainfall, grain yields, and food deficits. Hence, the agricultural capacity multiplied by rainfall (Eq. 7) is strongly related to per capita production. The inverse of this measure (food imbalance) is related to food aid. For each country, the food imbalance measure was regressed against 1979-2005 WFP humanitarian assistance. This gives a pragmatic means of translating changes in rainfall, cropped area, seed use and fertilizer use into an index of potential food aid requirements, supported empirically by historical aid figures. Due to the low per capita production, the resulting model performed well at a regional scale for Eastern and Southern Africa $(r=0.86, p=$ $1.6 \times 10^{-5}$ ) but was less accurate for the Western African countries $\left(r=0.48, p=4.8 \times 10^{-2}\right)$. Agricultural sufficiency may also be expressed as a theoretical food balance, based on an assumed annual cereals requirement of $190 \mathrm{~kg}$ per capita. Changes in the theoretical food balance (Eq. 5) 
Fig. 7 Main growing quarters (left panel: MAM, JJA, SON, DJF) and rainfall projections, expressed as \% change for 2050 for these quarters (right panel) as described by the hybrid dynamic-statistical precipitation reformulations for eastern and southern Africa. They are based on 21 st century projections of central Indian Ocean $\left[0-15^{\circ} \mathrm{S}\right.$, $\left.60-90^{\circ} \mathrm{E}\right]$ precipitation and global precipitation 1st principal components (IO and PC1, respectively). Changes in rainfall were obtained by multiplying the $\mathrm{IO}$ and $\mathrm{PC} 1$ regression parameters by the seasonally appropriate changes shown in Fig. 5

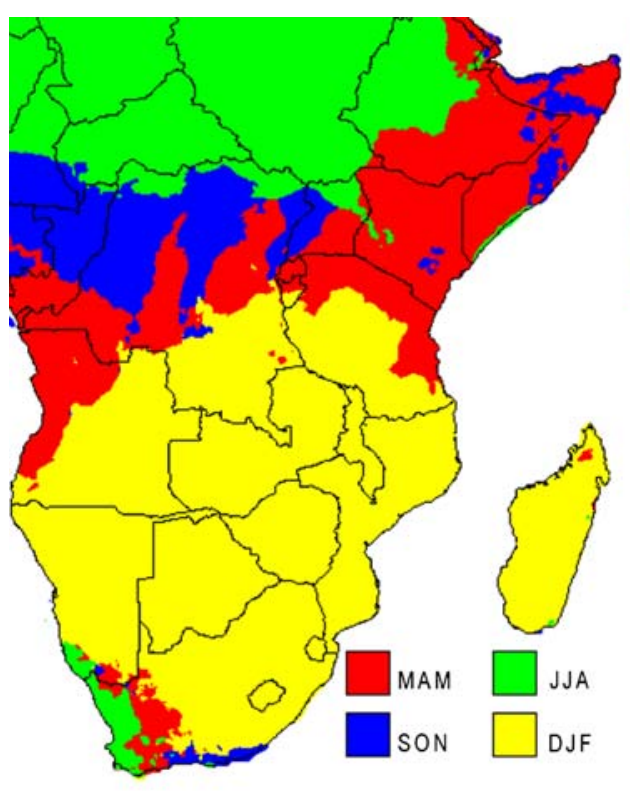

agree strongly with changes in WFP food aid, ${ }^{8}$ explaining $70 \%$ and $85 \%$ of their variance at national and regional scales.

Combining observed 1994-2003 agricultural capacity trends with our projected rainfall tendencies, this model can be used to project 2000 to 2030 food aid requirements (Fig. 8). We show historical WFP aid figures, historical model aid figures, and results from four sets of aid projection scenarios. The first scenario assumes that recent trends in population, rainfall, crop area, seed use, and fertilizer use continue for the next 30 years. The second scenario is the same, but with the change in rainfall inferred from our 1950-2005 Indian Ocean regressions and 21st century climate simulations. The third scenario assumes that precipitation levels will remain similar to those observed today. The fourth is an 'agricultural growth' scenario, in which observed rainfall trends continue, but per capita food availability is assumed to increase by $2 \mathrm{~kg}$ per person per year.

These results suggest that the interaction between drought and declining agricultural capacity (which includes population growth) may be explosive, dangerous and costly, with annual aid totals increasing by $83 \%$ by 2030 . The 'observed' versus 'projected' trends differ primarily for the Sahel (Fig. 8). The impact of climate change on the Sahel is keenly debated, and our analysis explicitly ignores influences from the Atlantic Ocean. Current agricultural capacity and rainfall trends will probably produce a $60 \%$

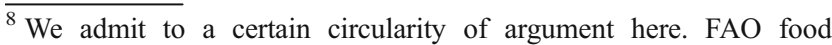
balance calculations have been used to guide WFP aid distributions, helping to enforce a tautological relationship. The data we choose to collect often follows closely our pre-existing observations, and tend to follow our theoretical paradigms (Kuhn 1962).
}

increase in food aid expenditures in the next two decades, and will probably lead to a $43 \%$ increase in food insecurity in Africa. These figures are significant because food aid is an indicator of many related problems including child malnutrition, as well as declines in health, productivity and economic growth (FAO, 2007). Including limitations in growth of harvested area and the impacts of increased growing season temperatures and potential evapotranspiration would inflate all these aid projections. Two hundred million sub-Saharan Africans were undernourished in 2002, and if the observed 1982-2002 trend continues this total may increase to almost 600 million people by 2030 .

\section{World yield analyses}

A set of projected agricultural yield values for the FAO regions (Fig. 9a) are those based on 1961-2007 linear trend models. Annual yield trends vary significantly by region. North America, Western Europe, and Eastern Asia have seen increases of over $700 \mathrm{~kg} \mathrm{ha}^{-1}$ annum $^{-1}$. Projections (Fig. 9a) for some of these regions in 2030 reach beyond $7,000 \mathrm{~kg} \mathrm{ha}^{-1}$. These projected yields may be beyond practical limits (Cassman et al. 2003). Western, Middle, and Eastern Africa, conversely, have exhibited very slow growth in yields (Table 5), with annual changes in yields of less than $110 \mathrm{~kg} \mathrm{ha}^{-1}$ annum $^{-1}$. Without accelerated agricultural development, 2030 yields will still be very low (Fig. 9a) The anticipated 2007 to 2030 transition in per capita production $\left[\mathrm{kg}\right.$ person $^{-1}$ annum $^{-1}$ ] has the 2007 value in $\mathrm{kg}$ per person per year to the left of the arrow and the 2030 prediction to the right.

Substantial reductions appear likely for Southern and Central America, Western and Eastern Africa, and Southern and Eastern Asia. Middle Africa and central Asia may 


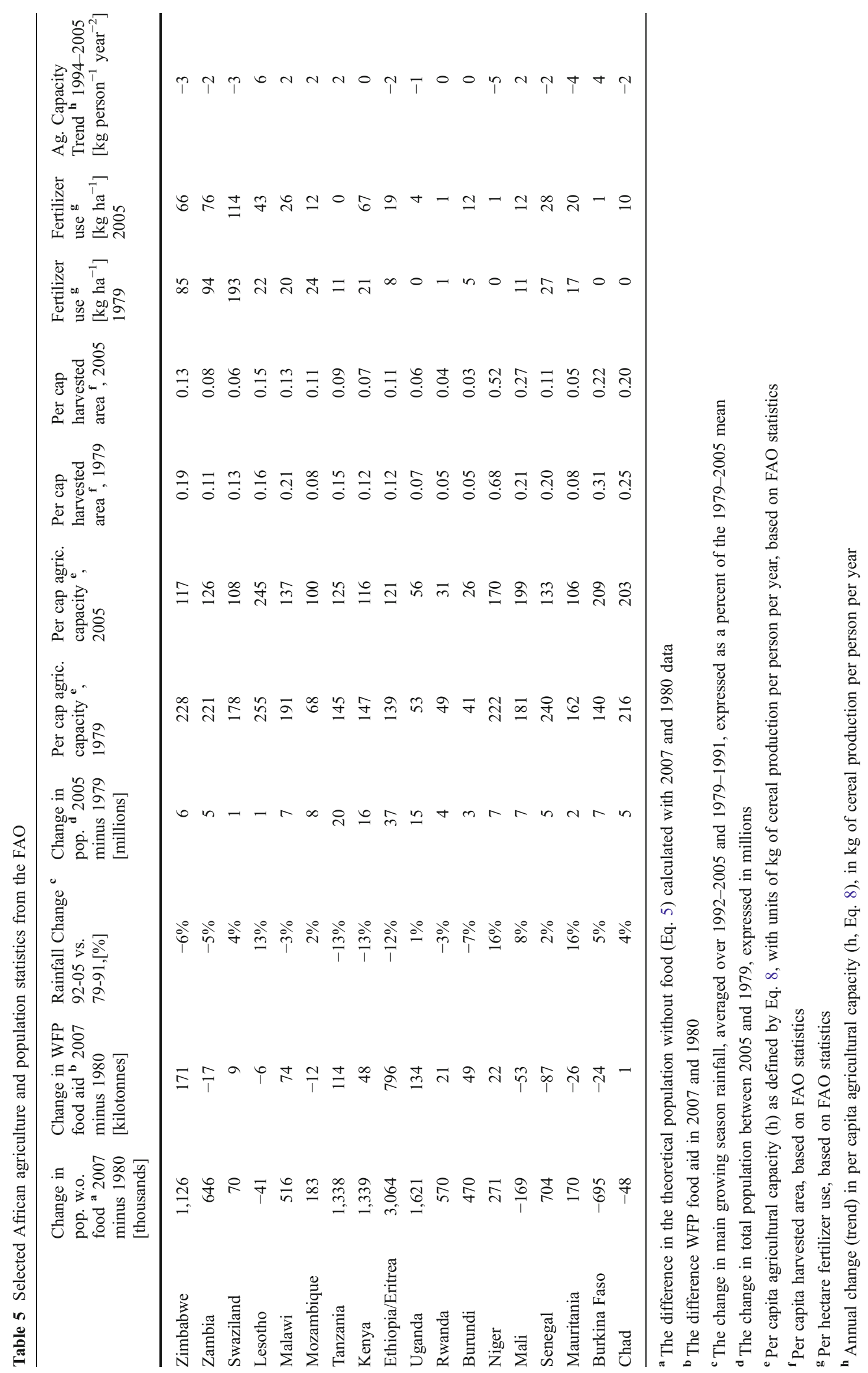




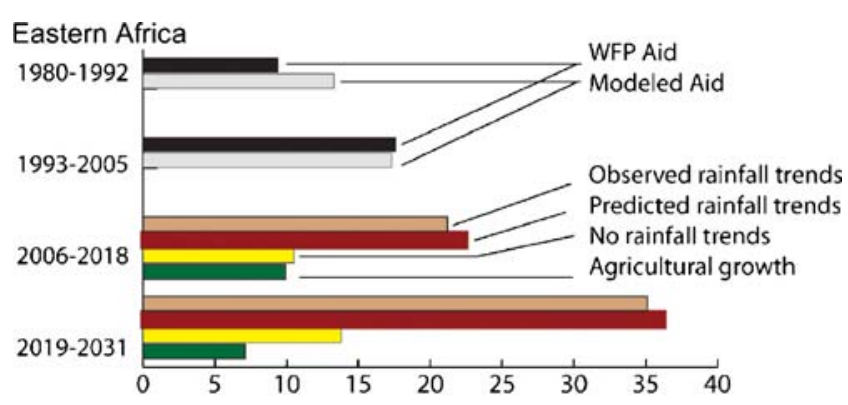

Southern Africa

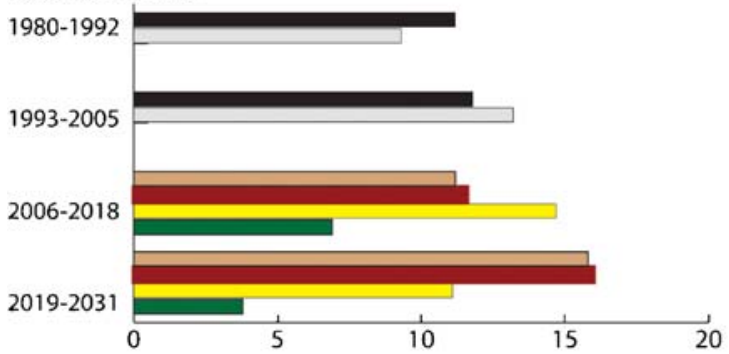

The Sahel

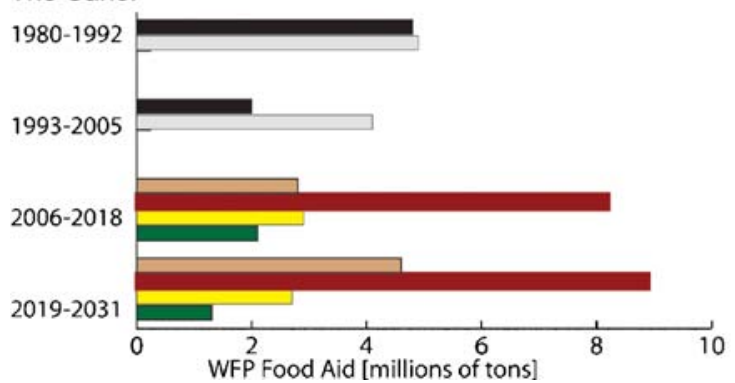

Fig. 8 Results from the modeling of the food balance indicator for the Sahel, Eastern Africa and Southern Africa. The black bars show historic WFP food aid, accumulated over 13 year intervals. The grey bars show empirical food aid estimates based on regressions with historic agricultural capacity and rainfall (cf. Eq. 7). The next set of bars show food aid projections based on four different assumptions of future scenarios. The light brown, dark brown, and yellow bars use historic agricultural capacity trends (cf. Eq. 8) combined with rainfall assumed to either i) trend along observed patterns, ii) trend according to rainfall predicted from Indian Ocean precipitation, or iii) to have no trend at all. The green bars show a scenario based on observed rainfall trends and an agricultural growth scenario

exhibit similar tendencies but were not modeled due to data limitations. Projected 2030 yields in Central America, Western and Eastern Africa, and Southern Asia remain below 4,000 kg ha ${ }^{-1}$ annum $^{-1}$. These two scenarios contrast 'business as usual' outcomes with plausible agricultural growth patterns. In the former, future yield trends are assumed to be the same as 1961-2007 yield trends (Table 3). In the latter scenario, we set baseline per capita cereal production targets and solve for the necessary yields in 2030 .

The 'business as usual' projected yields analysis (Fig. 9a) displays three key characteristics: i) yield trends and 2030 yield outcomes vary dramatically by region, ii) in developed nations a continuance of observed yield trends may result in physically unrealistic results, and iii) in Africa, Central
America and Southern Asia, a continuance of current trends will result in very low levels of food availability. Given increasing globalization and technological limits, one might imagine that yields would have converged since 1960. This has not been the case; rather the green revolution has followed a course in which the 'green get greener', with growth then slowing above 5,000 kg per ha per year. Yields in 1961 have been a very good predictor of yields in 2007 $\left(\mathrm{R}^{2}=0.8 .6\right)$; countries with lower yields have tended to increase their yields more slowly. This has enhanced differences between nations. In 1961 the highest regional yields were four times the lowest. This ratio rose to nine in 2007. A continuance of these trends will increase this ratio to 11 by 2030. As yield growth lags and per capita harvested areas decline, per capita cereal production will reach dangerous levels in Africa, Central America and Southern Asia.

As an alternative to using observed yield trends from Table 3, we can specify a target 2030 per capita production and solve directly for the required yield (Fig. 9b). This approach uses trends in per capita harvested area but then estimates 2030 yields algebraically. Two sets of cereal production targets were used. A minimal threshold of $190 \mathrm{~kg} \mathrm{ha}^{-1}$ annum $^{-1}$ was specified for African nations. The other countries were set to their 2007 values. This represents a modest 'agricultural growth' scenario, in which per capita production for most of the world maintains parity with current levels and Africa experiences modest gains.

This exercise suggests two salient results. First, the target yield gains for Africa appear small in magnitude but large in ratio. Looking at Eastern Africa, for example, we see that a transition from yields of $1,482 \mathrm{~kg}$ per hectare per year (Table 3) to $3,500 \mathrm{~kg}$ per hectare per year (Fig. 9b) would make the region relatively food secure. This is a large percent increase, but not technically impossiblefarming efficiencies would have to approach those used in Southern America in 2007 (Fig. 9a).

A second feature of Fig. $9 \mathrm{~b}$ is that maintaining current per capita cereal production levels in Northern America and Eastern Asia will require substantial increases in yields, much greater than those anticipated by historical trends. As per capita harvested area diminishes rapidly in these regions, very large increases in yields will be required to produce enough cereal to feed the future population at its current level of per capita cereal consumption. For Eastern Asia to maintain a per capita cereal production of $314 \mathrm{~kg}$ per person per year, yields will need to increase from their 2007 level of $5,418 \mathrm{~kg}$ per hectare per year (Table 3) to a very high yield of $8,600 \mathrm{~kg}$ per hectare per year. This may not be technically feasible or environmentally sustainable.

Although there is a substantial gap between maximum theoretical yield for the major world crops of maize, rice, and wheat and actual average yields, in recent years the gains in yields have declined. Rice yields in China and 


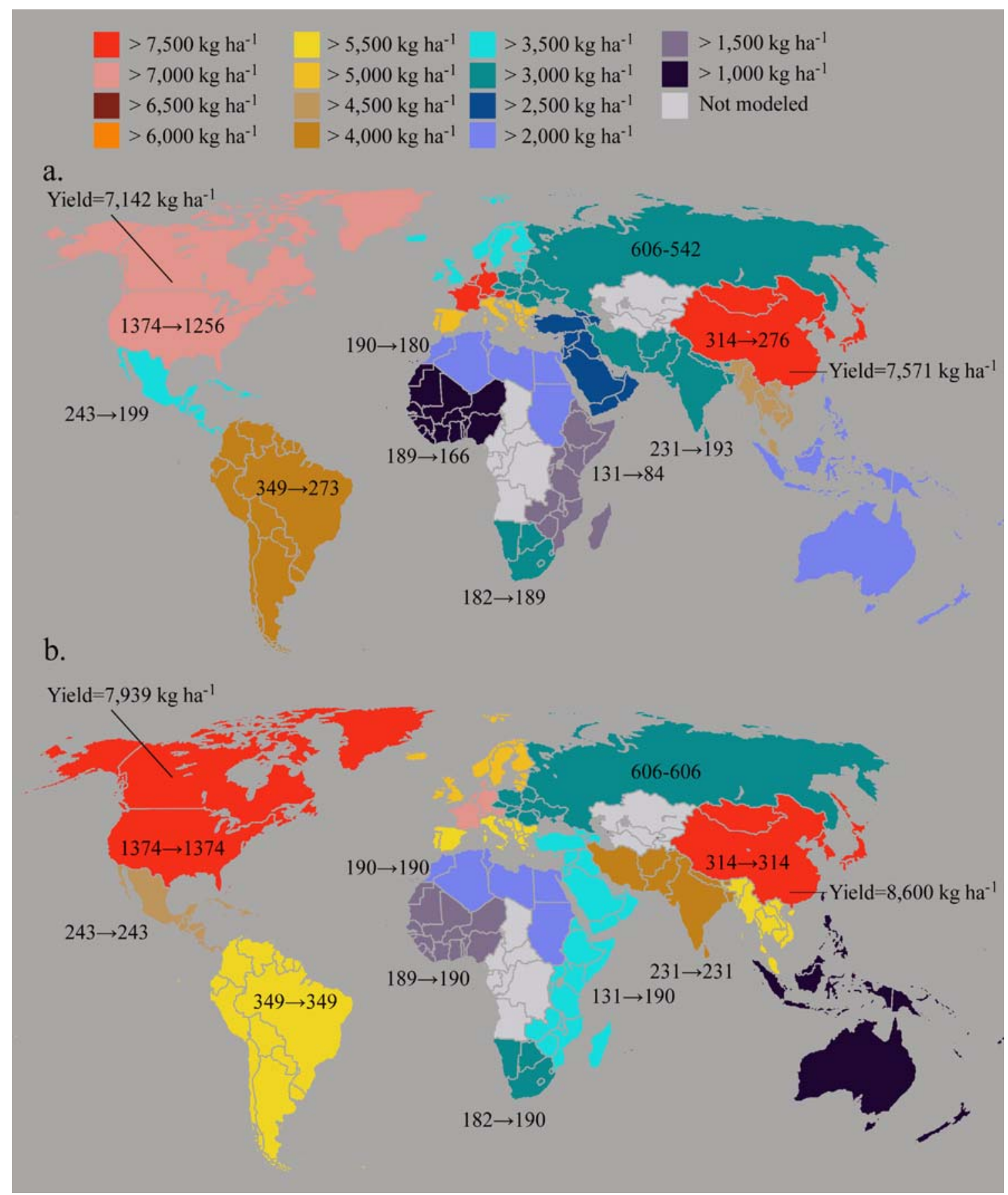

Fig. 9 Projected yields for 2030 (a) based on historical 1961-2007 trends (cf. Table 3). Values shown before and after arrows denote, respectively, the observed 2007 and projected 2030 per capita cereal production values in $\mathrm{kg}$ per person per year. Targeted yields (b) assuming the 2030 per capita production values on the right hand sides of the arrows
Indonesia and wheat yields in India and France, for example, have not increased substantially in the past decade (Cassman et al. 2003). Increasing yields beyond levels attained in these countries will require either enormous investments in freshwater irrigation systems or a transformation of the agricultural systems to incorporate new technological advances, both of which are highly unlikely in the next few decades. Investing in regions with extremely low agricultural productive capacity, therefore, will be a much less expensive way to improve global agricultural production. Bringing maize yields from 700 to $5,000 \mathrm{~kg}$ per hectare is far easier than increasing yields from 7,000 $\mathrm{kg}$ per hectare to $8,000 \mathrm{~kg}$ per hectare (Naylor 1996). This observation turns the standard food security 
paradigm on its head. With lower population growth and more effective farming practices, by 2030 it could be an agriculturally active Africa that helps alleviate global shortages of cereal production.

\section{Conclusions}

This paper has presented analyses which show that without concerted effort, today's food security crisis will continue to accelerate, robbing millions of people of their potential livelihoods. Food security and agricultural production are not directly linked. Politics, economics and access are also critical issues. In countries that experience significant levels of hunger, however, productive capacity is an important constraint, made more salient by increasing food price volatility. Investment in further productive capacity in regions with growing populations remains a challenge. Our results suggest that large-scale trends in yields and per capita harvested area (Fig. 2) are very predictable. It appears quite certain that the world will experience significant reductions in food availability as consumption demands increase due to biofuels and rising living standards.

Some parts of the developing world, such as Southern Asia, may have per capita production levels in 2030 similar to those of the 1960s or 1970s (Fig. 3). Other regions, such as Eastern Africa, face burgeoning food crises if current trends persist (Fig. 9). Greenhouse gas induced warming in the tropical Indian Ocean (Funk et al. 2008) and Pacific Ocean (Brown and Funk 2008) could exacerbate the likelihood of drought across many food producing regions (Figs. 6 and 7). Anthropogenic drought appears quite likely to affect chronically insecure Eastern Africa. Our food balance modeling (Fig. 8), however, suggests that agricultural development is likely to be a reasonable and effective mitigation strategy. The alternative may be a continued and expensive increase in chronic food aid.

Less certain but plausible climate change impacts on Southern Asia could also threaten agricultural production. Anthropogenic drought in Southern Asia (Fig. 6b), combined with declining per capita harvested areas, could lead to an explosive decrease in cereal availability, below the return to 1970 levels anticipated by our trend analysis (Fig. 3). Given the high degree of uncertainty surrounding all 21st century rainfall projections, and the strong links between these predictions and global food security, there will be a very strong economic and social value associated with more accurate and reliable regional rainfall predictions. Expanded support for precipitation modeling, especially in areas with mountainous terrain, could help address the emerging food crises of the next 30 years. This research could improve seasonal forecasts while better informing the IPCC assessments.
Many trends affect agricultural sustainability. It is important to recognize the complexity and interaction of these different factors. At the farm level, land modifications, plot landscape positioning, alternative crops or varieties, in-soil vegetative material and well-placed biodiversity can all play a role in countering unfavorable climatic events. Degradation in soil quality and in the overall natural resource base may threaten the long-run viability of several of the world's most intensive agricultural systems. Combined with monocultures of improved crops supported through high levels of inputs, much can be done to increase agricultural productivity in regions that currently produce $10 \%$ or less of their theoretical potential (Brown and Funk 2008). Agricultural innovations require political and economic stability, investment, and societal learning that must be sustained over relatively long periods. Some places in the developing world have managed to capitalize on new techniques and technology to significantly increase production, such as in Kenya's main maize growing districts where maize yields have increased from 3,000 to $5,000 \mathrm{~kg}$ per hectare in the past 8 years. $^{9}$ These gains are threatened when national political crises cut off roads, restrict access to critical inputs, and cause uncertainty in export contracts. The context in which production occurs is just as important as production itself.

Economic growth, improved food security, and widescale poverty reduction all require productivity gains in agriculture (Haggblade 2007). Agriculture serves as a powerful engine of poverty reduction, one which can bring the poorest a rapid improvement in income through direct technology transfer. According to Michael Lipton, "no country has achieved mass dollar poverty reduction without prior investment in agriculture" (Lipton 2005). Available evidence suggests that investment in public goods such as agricultural research, agricultural extension, and road networks constitutes one of the most effective tools available for stimulating economic growth and poverty reduction. Increasing per capita agricultural production in regions that currently have very low yields can be achieved with investment in these public goods (Platteau 1996, Lamb 2000). These investments can result in significant gains in incomes and reduction in poverty, which will reduce the number of people chronically malnourished.

Improved economic development, aid and agricultural policies, backed by adequate resources, can prevent humanitarian crises. Improved agricultural capacity is one of many reasonable ways to reduce vulnerability within Africa. Improved seed and fertilizer distribution can enhance yields, as can better land tenure and management

\footnotetext{
${ }^{9}$ Personal communication, Curt Reynolds, August 2008.
} 
policies. Expensive and potentially disruptive food aid shipments are much smaller than domestic African crop production. Since local cereal production is 100 times greater than food aid totals, modest increases in African food production could eradicate food production shortfalls. Our food balance modeling (Fig. 8), suggests that modest increases in yield would help eliminate the need for most external shipments of food aid.

Acknowledgements The authors would like to sincerely thank our anonymous reviewers, as well as colleagues from the USGS who graciously supplied their comments. Without their efforts this paper would be much less coherent. We would also like to express our gratitude to the UN Food and Agricultural Organization and the Program for Climate Model Diagnostics and Intercomparison for providing, respectively, access to the agriculture and climate modeling data used in this study. This research has been supported by funding from the US Agency for International Development Famine Early Warning System Network, the NASA Precipitation Monitoring Mission (grant NNX07AG26G), and a NASA decision support project (Cooperative Agreement Notice NN-H-04-Z-YO-010-C).

Open Access This article is distributed under the terms of the Creative Commons Attribution Noncommercial License which permits any noncommercial use, distribution, and reproduction in any medium, provided the original author(s) and source are credited.

\section{References}

Blaikie P, Brookfield HC (1987) Land degradation and Society. Methuen, London

Brown ME, Funk CC (2008) Food security under climate change. Science 319:580-581

Cassman, K. G. (2007). Climate change, biofuels, and global food security. Environmental Research Letters 2:doi:10.1088/17489326/1082/1081/011002.

Cassman KG, Dobermann A, Walters DT, Yang H (2003) Meeting cereal demand while protecting natural resources and improving environmental quality. Annual Review of Environment and Resources 28:315-358

Davis CG, Thomas CY, Amponsah WA (2001) Globalization and poverty: lessons from the theory and practice of food security. Am J Agric Econ 83:714-721

Delmer D (2005) Agriculture in the developing world: connecting innovations in plant research to downstream applications. Proc Natl Acad Sci 102:15739-15746

Devereux S, Maxwell S (2001) Food Security in Sub-Saharan Africa. ITDG, London

Fafchamps M (2004) Market Institutions in Sub-Saharan Africa: Theory and Evidence. MIT, Cambridge, MA

FAO (2007) The state of food and agriculture. United Nations Food and Agriculture Organization, Rome

Funk C, Dettinger MD, Brown ME, Michaelsen JC, Verdin JP, Barlow M, Hoell A (2008) Warming of the Indian Ocean threatens eastern and southern Africa, but could be mitigated by agricultural development. Proc Natl Acad Sci 105:1108111086

Haggblade, S. (2007). Returns to investment in Agriculture. [City]: Michigan State University.
Kates RW (2000) Cautionary tales: adaptation and the global poor. Climatic Change 45:5-17

Kuhn TS (1962) The structure of scientific revolutions. University of Chicago Press, Chicago

Lamb RL (2000) Food crops, exports, and the short-run policy response of agriculture in Africa. Agric Econ 22:271-298

Lipton M (2005) The family farm in a globalizing world: the role of crop science in alleviating poverty. International Food Policy Research Institute, Washington, DC

Lo HM, Sene A (1989) Human action and the desertification of the Sahel. ISSJ 121:449-456

Meehl GA, Covey C, Delworth T, Latif M, McAvaney B, Mitchell JFB, Stouffer RJ, Taylor KE (2007) THE WCRP CMIP3 multimodel dataset: a new era in climate change research. Bull Am Meteorol Soc 88:1383-1394

Naylor RL (1996) Energy and resource constraints on intensive agricultural production. Annu Rev Energy Environ 21:99-123

Parry ML, Canziani OF, Palutikof JP, Linden PJ, Hanson CE (eds) (2007) IPCC (2007) climate change 2007: impacts, adaptation and vulnerability. Contribution of working group II to the fourth assessment report of the intergovernmental panel on climate change. Cambridge University Press, Cambridge

Platteau J-P (1996) Physical infrastructure as a constraint on agricultural growth: the case of Sub-Saharan Africa. Oxf Dev Stud 24:189-219

Schmidhuber J, Tubiello FN (2007) Global food security under climate change. Proc Natl Acad Sci 104:19703-19708

Solomon S, Qin D, Manning M, Marquis M, Averyt K, Tignor MMB, Miller HL, Chen Z (2007) Climate change 2007-The physical science basis. Contribution of working group I to the fourth assessment report of the IPCC. Cambridge University Press, London

Turner BL, Hyden G, Kates RW (1993) Beyond intensification. In: Turner BL, Hyden G, Kates RW (eds) Population growth and agricultural change in Africa. University Press of Florida, Gainesville

Verdin J, Funk C, Senay G, Choularton R (2005) Climate science and famine early warning. Philosophical Transactions of the Royal Society B: Biological Sciences 360:2155-2168

Verhagen J, Put M, Zaal F, van Keulen H (2004) Climate change and drought risks for agriculture. In: Dietz AJ, Ruben R, Verhagen A (eds) The impact of climate change on drylands: With a focus on West Africa. Kluwer Academic Publishers, Dordrecht, pp 4959

Watts M (1989) The agrarian question in Africa: debating the crisis. Prog Hum Geogr 13:1-13

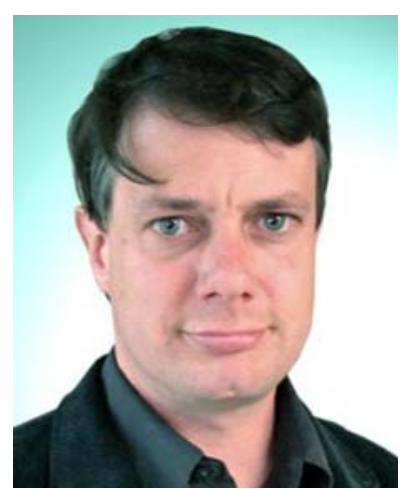

Chris Funk is a research geographer working with the US Geological Survey and the University of California, Santa Barbara Geography Department. Since 1999, he has worked closely with the USAID Famine Early Warning System Network. His research focuses on research supporting food security, tropical rainfall analysis and prediction, and African climate change. He works closely with the USGS Earth Resources Observation and Science Center, colleagues at UCSB's Climate Hazard Group, and African scientists in Nairobi, Gabarone and Niamey. 


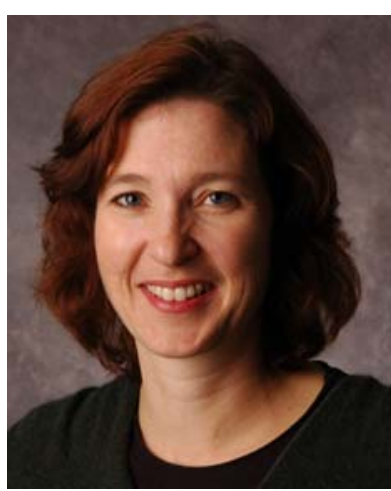

Molly E. Brown, PhD.: Born in Stonington, Connecticut in 1969, Dr. Brown graduated from Tufts University with a Bachelors of Science in Biology and Environmental Studies. After working for a year in Denver, Colorado, she joined the US Peace Corps as a Natural Resource Specialist in Senegal in 1992. Working with elementary school teachers in an arid region of Senegal, she developed an outdoor education program focusing on the role of trees in the savanna ecosystem. Upon return to the US, she entered graduate school in 1997, received a masters degree in December 1999 and a $\mathrm{PhD}$ in the summer of 2002 from the Department of Geography, University of Maryland at College Park. Her doctoral thesis focused on estimating the environmental dependence of millet prices in informal markets in three West African countries. During the past 10 years, Dr. Brown has worked with the GIMMS group at NASA's Goddard Space Flight Center to create a stable, 22-year, $8 \mathrm{~km}$ vegetation record from the NOAA-AVHRR series of instruments. Using these satellite data to investigate questions of climate, land use, and human-environmental interaction has been the main focus of her work. She has recently become a civil servant with the Biospheric Sciences Branch of NASA's Goddard Space Flight center. Currently she is involved in exploring decision making and the use of remote sensing data in governmental and non-governmental organizations whose work is influenced by climate and weather. She is married and has two children. 